\title{
Impact of early accelerated dose tissue plasminogen activator on in-hospital patency of the infarcted vessel in patients with acute right ventricular infarction
}

Evangelos Giannitsis, Juergen Potratz, Uwe Wiegand, Ulrich Stierle, Hasib Djonlagic, Abdolhamid Sheikhzadeh

\begin{abstract}
Objective-To assess the efficacy of early accelerated dose tissue plasminogen activator on in-hospital patency of the infarct related artery in patients with inferior myocardial infarction with and without right ventricular involvement.

Design-Single centre prospective assessment before discharge of infarct related vessel patency after early thrombolysis.

Setting-Tertiary cardiac referral centre at a university hospital.

Patients and methods -90 consecutive unselected patients with acute myocardial infarction, of whom $35(39 \%)$ had electrocardiographic evidence of right ventricular involvement (ST segment elevation greater than $0.1 \mathrm{mV}$ in right precordial lead V4R), were studied. All patients received accelerated dose tissue plasminogen activator $100 \mathrm{mg}$ within six hours from the onset of symptoms and had control angiography before discharge.
\end{abstract}

Main outcome measures-Infarct related coronary artery patency using the Thrombolysis in Myocardial Infarction (TIMI) grading system before discharge. Incidence of prolonged systemic hypotension, sinus bradycardia, complete atrioventricular block, and ventricular tachyarrhythmia during early hospitalisation.

Results-Despite aspirin and bolus heparinisation before thrombolysis and high dose heparinisation thereafter for at least 48 hours the infarct related artery was more likely to be occluded (TIMI 0 or 1 flow) in patients with right ventricular involvement than in those without $(69 v$ $29 \%, P<0.001)$, as shown by control angiography performed a mean of $12 \cdot 8$ days after thrombolysis. These findings may be explained, at least in part, by predominant involvement of the proximal right coronary artery (66 $v 31 \%, P<0.05)$ and a low cardiac output syndrome, being indirectly reflected by a high incidence of prolonged hypotension (26 v 7\%, $\mathbf{P}=$ $0 \cdot 02)$, bradycardia (34 v 14\%, $P=0.03)$, and complete atrioventricular block (37 $v$ $5 \%, P=0.0001$ ).

Conclusion-Primary angioplasty should be considered as the treatment of choice in patients with acute inferior infarction with right ventricular involvement because of the high failure rate of thrombolysis.
(Heart 1997;77:512-516)

Keywords: right ventricular infarction; thrombolysis; in hospital patency

Thrombolytic treatment has been shown to improve the clinical course of acute myocardial infarction in large randomised trials. ${ }^{12}$ Controversy exists, however, in some categories of patients, including those with late presentation, elderly patients, and those in cardiogenic shock, while the efficacy of thrombolysis has never been evaluated in others, such as those with right venticular infarction (RVI).

RVI represents a highly prevalent high risk subgroup among patients with inferior infarction, ${ }^{3}$ with a reported frequency of between $30 \%$ and $50 \%$, as diagnosed by electrocardiography. ${ }^{45}$ Typical features of RVI include proximal obstruction of the right coronary artery ${ }^{6-9}$ and occurrence of a cardiogenic shock-like low output syndrome. ${ }^{6}$ The first feature represents a major determinant for failed early reperfusion ${ }^{10}$ or late reocclusion, ${ }^{11} 12$ while the second may affect pharmacological reperfusion by impairment of flow mediated delivery of the fibrinolytic agent. ${ }^{13-15}$

The aim of the present study was to evaluate in-hospital patency of the infarcted vessel in a consecutive unselected series of patients with RVI at a mean of 12.8 days after thrombolysis. The effect of conditions commonly associated with a low output syndrome, such as the frequency of prolonged systemic hypotension, bradycardia, a high degree of atrioventricular block, and ventricular tachyarrhythmia during the acute phase of hospitalisation, on inhospital arterial patency were prospectively assessed.

\section{Material and methods}

PATIENTS

During a 24 month period from April 1993 to May 1995, we prospectively studied all patients with acute inferior myocardial infarction who were admitted to the intensive care unit, University Hospital of Luebeck. Acute myocardial infarction was diagnosed, according to World Health Organisation criteria, by typical chest pain lasting at least 30 minutes, ST segment elevation in at least two of the electrocardiographic leads II, III, and aVF, or an R/S ratio greater than 1 in V1 or V2, and an increase in creatine kinase activity of more than 
Table 1 Baseline characteristics

\begin{tabular}{lccl}
\hline & $\begin{array}{l}R V I \\
\text { present } \\
(n=35)\end{array}$ & $\begin{array}{l}R V I \\
\text { absent } \\
(n=55)\end{array}$ & $P$ \\
\hline Mean (SD) age (years) & $60(11)$ & $63(9)$ & NS \\
Previous infarctions (\%) & $4(11)$ & $4(7)$ & NS \\
Mean (SD) peak CK (IU/) & $1024(567)$ & $869(575)$ & NS \\
Mean (SD) peak CKMB (IU/I) & $90(51)$ & $89(56)$ & NS \\
Mean (SD) systolic blood pressure at & $120(31)$ & $132(29)$ & NS \\
admission (mm Hg) & $69(23)$ & $75(21)$ & NS \\
Mean (SD) heart rate at admission (beats/min) & $252(180)$ & NS \\
Mean (SD) onset symptoms to treatment (min) & $222(186)$ & $13(9)$ & NS \\
Mean (SD) time to coronary arteriography (days) & $13(7)$ & 13 & \\
\hline
\end{tabular}

CK, creative kinase; RVI, right ventricular infarction.

Table 2 Angiographic data

\begin{tabular}{llll}
\hline & $\begin{array}{l}R V I \\
\text { present } \\
(n=35)\end{array}$ & $\begin{array}{l}R V I \\
\text { absent } \\
(n=55)\end{array}$ & $P$ \\
\hline Multivessel disease ( $\geqslant 2$ VD) & $18(51)$ & $27(49)$ & NS \\
Significant LAD & $16(46)$ & $22(40)$ & NS \\
Proximal RCA & $23(66)$ & $17(31)$ & $<0.05$ \\
TIMI grade 0+1 & $24(69)$ & $16(29)$ & $<0.001$ \\
TIMI grade 2+3 & $11(31)$ & $39(71)$ & $<0.001$ \\
Mean (SD) LVEF (\%) & $50(14)$ & $57(14)$ & NS \\
\hline
\end{tabular}

Values are number of patients (\%) unless otherwise specified.

$\mathrm{VD}$, vessel disease; LAD, left anterior descending coronary artery; RCA, right coronary artery; LVEF, left ventricular ejection fraction; RVI, right ventricular infarction.

twice the normal value. At admission, a standard 12 lead electrocardiogram and additional right chest wall leads V3R-V6R were recorded. In the absence of right or left bundle branch block, RVI was diagnosed by the presence of ST segment elevation of at least $0.1 \mathrm{mV}$ in lead V4R.

Patients were included in the angiographic study if they were admitted within six hours of the onset of symptoms, and if they were eligible for thrombolytic treatment. Patients were excluded for any of the following reasons: lack of informed consent, active bleeding or haemorrhagic diathesis, cerebrovascular event or severe trauma within six months, prolonged cardiopulmonary resuscitation or major surgical procedure within two weeks, uncontrolled hypertension (greater than $180 / 120 \mathrm{~mm} \mathrm{Hg}$ ), and neoplasm. Patients with cardiogenic shock, uncomplicated resuscitation, a high degree of heart block, or who were elderly were not excluded. Thrombolysis was performed with an accelerated dose regimen of recombinant tissue plasminogen activator (rt-PA) $100 \mathrm{mg}$. Prethrombolytic treatment consisted of a bolus of heparin $5000 \mathrm{IU}$, followed by continuous infusion of $1200 \mathrm{IU} / \mathrm{kg} / \mathrm{h}$, and aspirin $250 \mathrm{mg}$. Postthrombolytic treatment consisted of heparin adjusted for activated partial throboplastin time for at least 48 hours, and aspirin $100 \mathrm{mg}$ daily.

\section{CORONARY ARTERIOGRAPHY AND LEFT \\ VENTRICULOGRAPHY}

Protocol coronary arteriography and left ventriculography were performed in all patients after a mean interval of 12.8 days using the femoral approach. Left ventriculography was performed in the right and left oblique projection. Left ventricular ejection fraction was measured using the area-length method. Arterial patency was estimated by two cardiologists not involved in the study using the Thrombolysis in Myocardial Infarction (TIMI) grading system. ${ }^{10}$
Grade 0 or 1 signified a closed artery, and grade 2 or 3 an open artery with normal or near normal blood flow.

\section{STATISTICAL EVALUATION}

Means (SD) were calculated for continuous variables and absolute and relative frequencies for discrete variables. Group differences in baseline characteristics and angiographic data were examined by a two-sample $t$ test for continuous variables and the $\chi^{2}$ test for discrete variables. All tests of significance were two tailed and used a significance level of $P<0.05$.

\section{Results}

\section{PATIENTS CHARACTERISTICS}

A total of 187 consecutive patients (120 men and 67 women of mean age (SD) $66.5(12.6)$ years) with acute inferior myocardial infarction were recruited. Ninety seven patients were excluded, 69 for late presentation, 21 for contraindications to thrombolysis, and seven for primary coronary angioplasty (PTCA).

Ninety patients fulfilled the inclusion criteria for the angiographic study, of whom 55 had inferior or posterior myocardial infarction without right ventricular involvement. Thirty five patients (39\%) had electrocardiographic evidence of RVI at admission. Table 1 shows the similarity in baseline characteristics for both groups.

Thrombolytic treatment was started within $4.0(3.0)$ hours from the onset of chest pain. Coronary angiography was performed after a mean interval of 12.8 (range 1-22) days after admission.

\section{ANGIOGRAPHIC DATA}

There was no significant difference in the left ventricular ejection fraction between patients with or without RVI. The severity or distribution of coronary arterial atherosclerosis was comparable in both groups. Coronary multivessel disease or significant stenosis of the left anterior descending artery was not associated with the presence of RVI (table 2).

RVI was associated with obstruction of the right coronary artery proximal to the origin of the right ventricular branch, while the majority of patients without right ventricular involvement had obstruction of either the left circumflex artery or the right coronary artery distal to the origin of the right ventricular branch.

Occlusion, defined as TIMI grade 0 or 1 flow, was present in $69 \%$ of patients ( 24 of 35 ) with RVI but only in $29 \%$ ( 16 of 55 ) of those without right venticular involvement. Normal coronary flow, defined as TIMI grade 3 , was present in 36 of 55 (65\%) patients without right ventricular involvement, but only in 10 of 35 (29\%) patients with RVI.

\section{ANALYSIS OF IN-HOSPITAL COMPLICATIONS COMMONLY ASSOCIATED WITH LOW OUTPUT SYNDROME}

Patients with RVI had a significantly higher probability to sustain in-hospital complications associated with low output syndrome than those without right ventricular involve- 
Table 3 Frequency of major in-hospital events

\begin{tabular}{lccl}
\hline & $\begin{array}{l}R V I \\
\text { present } \\
(n=35)\end{array}$ & $\begin{array}{l}R V I \\
\text { absent } \\
(n=55)\end{array}$ & $P$ \\
\hline Systemic hypotension (<100 mm Hg) & $9(26)$ & $4(7)$ & $0 \cdot 02$ \\
Bradycardia (<60 beats/min) & $12(34)$ & $8(15)$ & $0 \cdot 03$ \\
Cardiogenic shock & $6(17)$ & $4(7)$ & $\mathrm{NS}$ \\
Mobitz type 2 AV block & $7(20)$ & $5(9)$ & $\mathrm{NS}$ \\
Complete AV block & $13(37)$ & $3(5)$ & $0 \cdot 0001$ \\
Ventricular tachycardia & $10(29)$ & $14(25)$ & $\mathrm{NS}$ \\
Ventricular fibrillation & $7(20)$ & $3(5)$ & $0 \cdot 03$ \\
Congestion & $4(11)$ & $2(4)$ & $\mathrm{NS}$ \\
Myocardial reinfarction & $5(14)$ & $2(4)$ & $0 \cdot 06$ \\
Reischaemia & $14(40)$ & $16(29)$ & $\mathrm{NS}$ \\
Death & $1(3)$ & 0 & \\
\hline
\end{tabular}

Values are number of patients (\%) unless otherwise specified

$\mathrm{RVI}$, right ventricular infarction; $\mathrm{AV}$, atrioventricular. a longer mean interval from rt-PA infusion to peak creatine kinase level (19 $v 11$ hours, $\mathrm{P}<$ $0.03)$, a lower frequency of haemorrhagic necrosis $(25 v 71.4 \%, \mathrm{P}<0.04)$, and a higher frequency of luminal thrombus in the infarct related artery (25 $v 21.4 \%, P=0.054)$ were associated with evidence of RVI. It was concluded that successful thrombolysis might prevent RVI.

All other studies, ${ }^{718-20}$ each involving no more than 200 patients with inferior myocardial infarction, made an indirect assessment of the effect of thrombolytic treatment, focusing on the improvement in right ventricular function and survival. Interestingly, the data conflict, even with respect to beneficial effects of thrombolysis in terms of right heart function or survival. Verani $e t a l^{7}$ showed that improvement in right ventricular function was independent of reopening of the infarct related artery. This finding was supported by Roth et $a l^{18}$ who reported on 65 patients with predominant right ventricular involvement. Patients had a beneficial course and showed spontaneous improvement of right ventricular function independent of early thrombolytic treatment. Spontaneous improvement has even been reported for patients with predominant right ventricular dysfunction who did not receive thrombolytic treatment. ${ }^{6}$ In contrast, Schuler et al ${ }^{19}$ showed rapid improvement of an initially depressed right ventricular function and improved survival in 12 of 19 patients who had successful recanalisation. Zehender $e t$ $a l^{20}$ showed a significant reduction in mortality and in-hospital complications associated with thrombolytic treatment among patients with an inferior myocardial infarction that was almost exclusively restricted to those with RVI.

In our study, pretreatment diagnosis of RVI was performed with electrocardiography to allow a prospective evaluation of late vessel patency after thrombolysis.

Right precordial electrocardiography is the most readily available, simplest non-invasive technique for the detection of acute RVI. From the electrocardiographic criteria used to diagnose RVI, the highest accuracy is offered by the criterion of ST segment elevation of at least $0.1 \mathrm{mV}$ in the right precordial lead V4R. ${ }^{21}$ Sensitivity ranges from $83-100 \%$, specificity from $68-95 \%$, and diagnostic accuracy from $70-93 \% .{ }^{21-24}$ The incidence of RVI in the present study using significant ST elevation in lead V4R was 39\%; a consistent finding with the commonly assessed $30-50 \%$ incidence.

An accelerated rt-PA treatment in combination with pretreatment bolus heparinisation and antiplatelet treatment followed by aPTT adjusted continuous heparinisation for at least 48 hours was chosen to provide the most advantageous thrombolytic regimen. ${ }^{25} \mathrm{We}$ tried to exclude a selection bias by including consecutive patients who fulfilled the inclusion criteria and received thrombolysis, regardless of age, prior myocardial infarction, cardiogenic shock, or uncomplicated resuscitation, thus including even high risk patients. A refer-
The second study involved 22 patients with inferior myocardial infarction who died soon after receiving thrombolytic treatment. ${ }^{17}$ The postmortem examination showed that the absence of coronary reperfusion, diagnosed by 
ral bias was ruled out by excluding patients who were referred from other hospitals after failed thrombolysis. Because of the timing of control coronary angiography after a mean of $12 \cdot 8$ days, however, we were unable to provide any angiographic data regarding recanalisation or reocclusion rates.

In our study, the late patency rate was found to be as low as $29 \%$ in patients with RVI, in contrast to $67 \%$ in those without right ventricular involvement. There is an obvious lack of long term benefit from lysis as suggested by a late patency rate of $29 \%$, which is comparable to late patency rates in patients with infarcts receiving only high dose heparin and aspirin. ${ }^{26}$

Angiographic data from the GUSTO trial ${ }^{25}$ showed that normal coronary flow was present in only $54 \%$ of patients after successful thrombolysis with an accelerated dose regimen of rtPA. In addition, reocclusion has been identified in up to $30 \%$ of patients after three months, being most frequent in the first week after lysis, thus leaving less than $50 \%$ of patients with successfully sustained full reperfusion. ${ }^{27-29}$ In addition, two features of RVI are known adversely to affect coronary vessel patency. First, reocclusion after lysis is more common when the right coronary is involved in the infarct. ${ }^{11}{ }^{12}$ Second, prolonged hypotension, bradycardia, complete atrioventricular block, frequently encountered during RVI, result in a low cardiac output syndrome, thus impairing flow mediated delivery of the fibrinolytic agent. ${ }^{13} 14$ In support of our hypothesis, the incidence of a low output syndrome was present in as many as $73 \%$ of patients with RVI. ${ }^{6}$ The authors state that the high incidence of bradyarrhythmia may account in part for the low cardiac output syndrome. In addition, low heart rate may acutely aggravate right ventricular ischaemia, reduce right ventricular contractility and compliance, and decrease cardiac output as a result of an ineffective Frank-Starling mechanism. ${ }^{30}$ Concordantly, thrombolysis has been found to be less effective in the setting of cardiogenic shock or hypotension. ${ }^{31} 32$

In our study the incidence of prolonged hypotension, bradycardia, complete atrioventricular block, and ventricular fibrillation was significantly higher in patients with RVI than in those without. Frequencies with which major complications are encountered in the setting of RVI commonly range from $13-48 \%$ for high degree atrioventricular block, ${ }^{4-633}$ from $24-41 \%$ for shock with low output, ${ }^{4-6}$ from $16-22 \%$ for ventricular fibrillation, ${ }^{46}$ and approximately $60 \%$ for hypotension with bradycardia. ${ }^{6}$

In contrast, patients in whom reperfusion failed to restore patency had a higher rate of morbidity, including sustained hypotension, a high degree of atrioventricular block, ${ }^{12}$ and sustained ventricular tachycardia and fibrillation, ${ }^{34}$ than those with successfully sustained patency.

Therefore, the cause-effect relation among these particular haemodynamic sequelae and vessel patency is difficult to distinguish.

\section{Conclusions}

Our findings suggest that rt-PA $100 \mathrm{mg}$ (accelerated dose) fails to achieve an acceptable late patency in patients with RVI. The exact pathomechanism remains unclear, as we were unable to assess early patency and reocclusion rates. Whether other thrombolytic regimens, including non-fibrin selective agents, are more efficacious in the setting of RVI is a question to be assessed in further studies.

While the role of mechanical reperfusion is still controversial for the general population, primary angioplasty may be the preferential treatment for patients in certain high risk subgroups including those with RVI. This hypothesis is primarily based on our own, yet unpublished data, and a recently published retrospective study. ${ }^{9} \mathrm{Kinn}$ et $a l^{9}$ showed that PTCA was successful in 17 of 27 patients and led to prompt haemodynamic improvement in right ventricular function, even after a mean interval to treatment beyond six hours.

However, a concordant benefit has not been confirmed for rescue PTCA of the right coronary artery. Two large scale series ${ }^{35}{ }^{36}$ raised the possibility that rescue of the right coronary could be detrimental compared with rescue of the left anterior descending artery. Patients sustained significantly more intraprocedural adverse effects, including ventricular fibrillation, hypotension, severe bradycardia, Mobitz type 2, or complete atrioventricular block as well as abrupt closure, and subsequent reocclusion. The mechanism is unclear but may be related to an exaggerated Bezold-Jarisch reflex, distal showering of thrombi into the microcirculation, or reperfusion injury.

In conclusion, this provocative report provides the first preliminary evidence that early conventional thrombolysis in patients with RVI fails to achieve in-hospital arterial patency. Further controlled studies are mandatory to confirm these findings and to assess the benefit of thrombolysis versus primary coronary angioplasty.

\section{Limitations}

Several shortcomings of our study need to be emphasised. First, the timing of control angiography was not suitable for the assessment of early infarct vessel patency or reocclusion rates. Our intention was to obtain as much information as possible about vessel patency, avoiding more than one angiographic procedure in the same patient. Therefore, elective coronary angiography representing the less hazardous approach for the individual patient was performed before discharge unless emergency angiography was required earlier.

Second, the study was limited by a relatively small sample size. Although baseline characteristics between both infarct groups were not statistically different, theoretically type 2 error could account for differences in outcome. In view of very small sample sizes generally evaluated in most previous studies, ${ }^{471819}$ the largest group not exceeding more than 100 patients with RVI, our sample size is competitive and represents the only available prospective study 
focusing on vessel patency after thrombolytic treatment.

Finally, there is only indirect evidence of a low output syndrome as suggested by a high incidence of rhythm and conduction disorders, prolonged hypotension and cardiogenic shock, as haemodynamic monitoring with a Swan-Ganz catheter was performed only when overt haemodynamic deterioration was present. Furthermore, patients were not randomised to receive either thrombolysis or primary PTCA, as the study was started when primary angioplasty was not readily available at our institution.

1 Fibrinolytic Therapy Trialists (FTT) Collaboratory Group Indications for fibrinolytic therapy in suspected acute myocardial infarction: collaborative overview of early mortality and major morbidity results from all randomised trials of more than 1000 patients. Lancet 1994, 343:311-22.

2 Grines CL, De Maria AN. Optimal utilization of thrombolytic therapy for acute myocardial infarction: concepts and controversies. F Am Coll Cardiol 1990;16:223-31.

3 Berger PB, Ryan TJ. Inferior myocardial infarction-high risk subgroups. Circulation 1990;81:401-11.

4 Zehender M, Kasper W, Kauder E, Schönthaler M, Geibel A, Olschewski $M$, et al. Right ventricular infarction as an independent predictor of prognosis after acute inferior myocardial infarction. $N$ Engl f Med 1993;328:981-8.

5 Andersen HR, Nielsen D, Lund O, Falk E. Prognostic significance of right ventricular infarction diagnosed by ST elevation in right chest leads V3R to V7R. Int $\mathcal{f}$ Cardiol 1989;23:349-56.

6 Shah PK, Maddahi J, Berman DS, Pichler M, Swan HJC. Scintigraphically detected predominant right ventricular dysfunction in acute myocardial infarction: clinical and dysfunction in acute myocardial infarction: clinical and
hemodynamic correlates and implications for therapy hemodynamic correlates and implications for ther

7 Verani MS, Tortoledo FE, Batty JW, Raizner AE. Effect of coronary artery recanalization on right ventricular funccoronary artery recanalization on right ventricular function in patients with acute my

8 Lew AS, Laramee P, Shah PK, Maddahi J, Peter T, Ganz W. Ratio of ST-segment depression in lead V2 to ST segment elevation in lead aVF in evolving inferior acute myocardial infarction: an aid to the early recognition of right ventricular ischemia. $A m$ f Cardiol 1986;57: 1047-51

9 Kinn JW, Ajluni SC, Samyn JG, Bates ER, Grines CL O'Neill W. Rapid hemodynamic improvement after reperfusion during right ventricular infarction. $₹ \mathrm{Am} \mathrm{Coll}$ Cardiol 1995;26:1230-4

10 Chesebro JH, Knatterud G, Roberts R, Borer J, Cohen LS Dalen J, et al. Thrombolysis in Myocardial Infarction (TIMI) Trial, Phase I: a comparison between intravenous tissue plasminogen activator and intravenous streptokinase. Circulation 1987;76:142-54

11 Bates ER, Califf RM, Stack RS, Aronson L, George BS, Candela RJ, et al. Thrombolysis and Angioplasty in
Myocardial Infarction (TAMI-1) Trial: influence of infarct location on arterial patency, left ventricular funcinfarct location on arterial patency, left ventricular
tion and mortality. $\mathcal{F} \mathrm{Am}$ Coll Cardiol 1989;13:12-8.

12 Ohman EM, Califf RM, Topol EJ, Candela R Abbottsmith C, Ellis S, et al. Consequences of reoccluAbbottsmith C, Ellis $\mathrm{S}$, et al. Consequences of reocclu-
sion after successful reperfusion therapy in acute myocarsion after successful reperfusion therapy in acut
dial infarction. Circulation 1990;82:781-91.

13 Prewitt RM, Downes AMT, Gu S, Chan SM, Ducas J. Effects of hydralazin and increased cardiac output on
recombinant tissue plasminogen activator-induced recombinant tissue plasminogen activator-induced thrombolysis in

14 Prewitt RM, Gu S, Garber PJ, Ducas J. Marked systemic hypotension depresses coronary thrombolysis induced by intracoronary administration of recombinant tissue-type plasminogen activator. $\mathcal{F} \mathrm{Am}$ Coll Cardiol 1992;20 1626-33.

15 Bates ER, Topol EJ. Limitations of thrombolytic therapy for acute myocardial infarction complicated by congestive heart failure and cardiogenic shock. $\mathcal{F} \mathrm{Am}$ Coll Cardio 1991;18:1077-84.

16 Berger PB, Ruocco NA, Ryan TJ, Jacobs AK, Zaret BL Wackers FJ, et al. Frequency and significance of right ventricular dysfunction during inferior wall left ventricula myocardial infarction treated with thrombolytic therapy (results from the Thrombolysis in Myocardial Infarction
II Trial). Am $\mathcal{f}$ Cardiol 1993;71:1148-52.

17 Kalan JM, Gertz SD, Kragel AH, Berger PB, Roberts WC Ryan TJ. Effects of tissue plasminogen activator therapy on the frequency of acute right ventricular myocardia infarction associated with acute left ventricular infarction Int $\mathcal{F}$ Cardiol 1993;38:151-8.

18 Roth A, Miller HI, Kaluski E, Keren G, Shargorodsky B Krakover R, et al. Early thrombolytic therapy does not enhance the recovery of the right ventricle in patients with acute inferior myocardial infarction and predominant right ventricular involvement. Cardiology 1990;77 40-9.

19 Schuler G, Hofmann M, Schwart F, Mehmel H, Manthey J, Tillmanns $\mathrm{H}$, et al. Effect of successful thrombolytic therapy on right ventricular function in acute inferior

20 Zehender M, Kasper W, Kauder E, Geibel A, Schönthaler $M$, Olschewski $M$, et al. Eligibility for and benefit of thrombolytic therapy in inferor myocardial infarction: focus on the prognostic importance of right ventricular focus on the prognostic importance of right
infarction. $\mathcal{F}$ Am Coll Cardiol 1994;24:362-9.

21 Zehender M, Kasper W, Kauder E, Schönthaler M Olschewski $M$, Just $H$. Comparison of diagnostic accuracy, time dependency, and prognostic impact of abnormal $Q$ waves, combined electrocardiographic criteria, mal $\mathrm{Q}$ waves, combined electrocardiographic criteria, and ST segment abnormalities in
tion. Br Heart $f$ 1994;72:119-24.

22 Braat SH, Brugada P, De Zwaan C, Coenegracht JM Wellens $\mathrm{HJJ}$. Value of electrocardiogram in diagnosing right ventricular involvement in patients with an acute inferior wall myocardial infarction. Br Heart $\mathcal{f} 1983 ; 49$ 368-72.

23 Klein HO, Tordjman T, Ninio R, Sareli P, Oren V, Lang $\mathrm{R}$, et al. The early recognition of right ventricular infarc-
tion: diagnostic accuracy of the electrocardiographic $\mathrm{V} 4 \mathrm{R}$ lead. Circulation 1983;67:558-65.

24 Lopez-Sendon J, Coma-Canella I, Alcasena S, Seoane J, Gamallo C. Electrocardiographic findings in acute right ventricular infarction: sensitivity and specifity of electrocardiographic alterations in right precordial leads V4R V3R, V1, V2 and V3. F Am Coll Cardiol 1985;6:1273-9.

25 The GUSTO angiographic investigators. The effects of tissue plasminogen activator, streptokinase, or both on coronary-artery patency, ventricular function, and survival after acute myocardial infarction. $N$ Engl $f \mathrm{Med}$ vival after acute myo.

26 Topol EJ, Califf RM, Vandormael M, Grines CL, George BS, Sanz ML, et al. A randomized trial of late reperfusion therapy for acute myocardial infarction. Circulation 1992; therapy for

27 Verheugt FWA, Meijer A, Lagrand WK, van Eenige MJ Reocclusion: the flip side of coronary thrombolysis. $₹ \mathrm{Am}$ Coll Cardiol 1996;27:766-73.

28 Lincoff AM, Topol EJ. Illusion of reperfusion. Does anyone achieve optimal reperfusion during acute myocardia infarction? Circulation 1993;87:1792-805.

29 Meijer A, Verheugt WA, Werter CJPJ, Lie KI, van der Pol JMJ, van Eenige MJ. Aspirin versus coumadin in the prevention of reocclusion and recurrent ischemia after successful thrombolysis: a prospective placebo-controlled angiographic study. Circulation 1993;87:1524-30.

30 Lopez-Sendon J, Coma-Canella I, Gamallo C. Sensitivity and specifity of hemodynamic criteria in the diagnosis of acute right ventricular infarction. Circulation 1981;64: 515-25.

31 Gruppo Italiano per lo studio della Streptochinasi nell'infarto miocardico (GISSI). Effectiveness of intravenous trombolytic treatment in acute myocardial infarction. Lancet 1986;i:349-60.

32 Kennedy JW, Gensini GG, Timmis GC, Maynard C. Acute myocardial infarction treated with intracoronary streptokinase: a report of the Society for Cardiac Angiography. Am f Cardiol 1985;55:871-7.

33 Braat SH, de Zwaan C, Brugada P, Coenegracht JM Wellens HJ. Right ventricular involvement with acute inferior wall myocardial infarction identifies high risk of inferior wall myocardial infarction identifies high risk of developing atrioventricular nodal cond
bances. Am Heart f 1984;107:1183-7.

34 Berger PB, Ruocco NA, Ryan TJ, Frederick MM, Podrid $\mathrm{PJ}$. Incidence and significance of ventricular tachycardia and fibrillation in the absence of hypotension or hear failure in acute myocardial infarction treated with recombinant tissue-type plasminogen activator: results from the Thrombolysis in Myocardial Infarction (TIMI) Phase I Trial. $\mathcal{F}$ Am Coll Cardiol 1993;22:1773-9.

35 Gacioch GM, Topol EJ. Sudden paradoxical clinical deterioration during angioplasty of the occluded right coronary artery in acute myocardial infarction. $\mathcal{F} \mathrm{Am}$ Coll Cardio 1989;14:1202-9.

36 Abbottsmith CW, Topol EJ, George BS, Stack RS Kereiakes DJ, Candela RJ, et al. Fate of patients with acute myocardial infarction with patency of the infarctrelated vessel achieved with successful thrombolysis versus rescue angioplasty. $\mathcal{F} \mathrm{Am}$ Coll Cardiol 1990;16:770-8. 